\title{
Laptop cooling numerical simulation using Computational Fluid Dynamics
}

\author{
Syamsuri ${ }^{1}{ }^{*}$, Z.A. Fairuz ${ }^{2}$, K.D.T. Alfonsus ${ }^{3}$ \\ Department of Mechanical Engineering, Institut Teknologi Adhi Tama Surabaya \\ ${ }^{*}$ Corresponding author: syamsuri@itats.ac.id
}

\begin{abstract}
Laptop's cooling solution is very important. In some cases, due to poor cooling an over heat on the mother board, main chip, and other components occurs, so that the laptop is quickly broken. Therefore it is necessary to know the temperature distribution so that over heat can be overcome. One of the methods to determine the temperature distribution in this final project is a flow simulation, using CFD (Computational Fluid Dynamics), 3D method with the variation if different air flow velocity, i.e. $5 \mathrm{~m} / \mathrm{s}, 10 \mathrm{~m} / \mathrm{s}$, and $15 \mathrm{~m} / \mathrm{s}$. The higher the air flow rate, the higher the cooling occurs. From the temperature contours it is shown that the hot temperature is built up on the back of the heat sink. The results of the validation of this study and previous studies obtained an error that occurred was around $4 \%$.
\end{abstract}

Keywords: CFD, variation of air flow velocity, laptop.

\section{Introduction}

Nowadays, many developed countries around the world are making technologies that are evolving and modernize. The technology is widely used for research about combining free convection heat transfer and heat transfer from radiation.

Forced convection is an occurrence where the heat flow is forced with aid of some devices, such as a fan or blower, to flow to destination. Forced convection included, for example, in car engine cooling system, hairdryer and the nuclear power plant reactor.

Convection heat transfer depends on the viscosity of the fluid's thermal properties. This is understandable since viscosity affects the velocity profile, thus, affecting the rate of energy transfer in the wall area. In the heat transfer process by forced convection, where the flow is induced by several ways that come from fans, pumps, and blowers. This research is doing to see the phenomenon of the effect of cooling and flow characteristics when the velocity varies. The aim of this research is to use CFD software to select the numerical simulation of the cooling on laptop.
The application in this study was carried out using CFD software with numerical visualization. CFD software is used as speed is varies to include details about the results of the cooling and flow characteristics. The simulation results are then reprocessed to obtain the profiles of velocity and temperature.

Research on numerical simulations has been carried out, among others: Dedy Zulhidayat Noor (2009) [1], examined the boundary method for simulating fluid-solid interaction interactions by adopting the direct-forcing method and adding NavierStokes equations to adjust interactions between solids and substances liquid.

Anusaya et al (2014) [2], investigated numerical simulations on rigs equipped with eclectic heated horizontal heating tubes with different power supplies. The fluidized bed temperature profile which was evaluated for different positions using axial method in the fluidized substance. The results show that with increasing particle size and heat flux the temperature distribution decreases where the temperature also increases with increasing air velocity.

Jing Zhao et al (2019) [3] examined the numerical simulation and the stochastic 
ensemble method in forecasting many step wind speeds. The simulation shows the proposed method effectively reduces numerical simulation uncertainty, and works better than other models. The results from the simulation also show how fewer members of the ensemble might be better than those using one combination. This study is very important for both theoretical and real applications for numerical estimates of wind velocity at local locations.

Xin hao et al (2019) [4] examined numerical simulations of the thermal characteristics of the pile foundations on the Qinghai-tibet area in Beiluhe warm permafrost. 3D numerical models are performed to analyze thermal disturbances and the freezing process, based on observational data. The results shown are that the thickness of the small ring thermal disturbance at the foundation of the pile is $1.6 \mathrm{~m}$, meaning twice the pile's diameter.

Zerui Sun et al (2020) [5] investigated the $\mathrm{SPH} 2 \mathrm{D} / 3 \mathrm{D}$ numerical simulation analysis in the blasting process and the morphological distribution of faceto-face double vertical welding. Two composites trigger the double vertical blast that can add more energy-efficient utilities. Results of this research are the presence of well reproduced interface and flow waves inside the 2D model.

Abdulmajeed A. Ramadhan et al (2018) [6] examined numerical simulations using the EHD/Electrohydrodynamic air blower cooling system method on laptops. The numerical demonstration results of the EHD cooling system are very compatible with their effectiveness in performance and temperature control with a safe and typical operating range.

Hsiao- Kang Ma et al (2009) [7] investigated the development of the OAPCP-Micro pump cooling fluid system method on laptops. What is being developed is an actuator in the form of a piezoelectric micro pump that can be added to the laptop cooling system in combination with a cold plate space. The new design of the cooling method can be proven to have a stable performance at total thermal resistance due to high flow rates.

Syamsuri (2017) [8] examined laptop cooling with numerical simulations and variations in air flow velocity. From the results obtained the speed of airflow through the heat sink is the highest heat transfer. Where at a speed of $15 \mathrm{~m} / \mathrm{s}$ is the most efficient speed.

Syamsuri et al (2018) [9] investigated the effects of the angle of attack on the characteristics of bicycle racing helmets using CFD applications. The study used variations of Reynold Number and 4 variations of the angle of attack. The results obtained the drag coefficient at the angle of attack 0-20 degrees tends to decrease and at 20-30 degrees the coefficient of drag tends to increase.

Based on previous studies The aim of this study is to figure out the effect of wind speed on heating that occurs on a laptop, which region has the greatest heat source and which area does not. Analysis uses numerical computational methods because in many cases the method can solve shirts well and quickly.

\section{Research Method}

Model preparation is very important before entering the simulation stage. Because every component is very influential with this process. The components to be prepared before the simulation is completed are as:

\section{Pre-Processing}

The first stage is the pre-processing stage. This stage is a very early stage for modeling with CFD. These stages include making the project from the simulation flow, Level of Initial Mesh, Model configuration of CFD, and determining the rotor speed of the van.

2. Solver

Problem solving stage using CFD software that starts from the Engineering database, External fan inlet and boundary conditions, defining the heat source, defining the engineering goals, and computational domain. 


\section{Post-processing}

The last step is post-processing, which is the process where the results obtained are displayed. The data taken is the contour of the cooling speed.

The image model for the simulation can be seen of Figure 1 where it is equipped with Heat Sink, PCB, Small Chips, Inlet Fan, Main Chip, Capacitor, Power Supply and Mother Board.

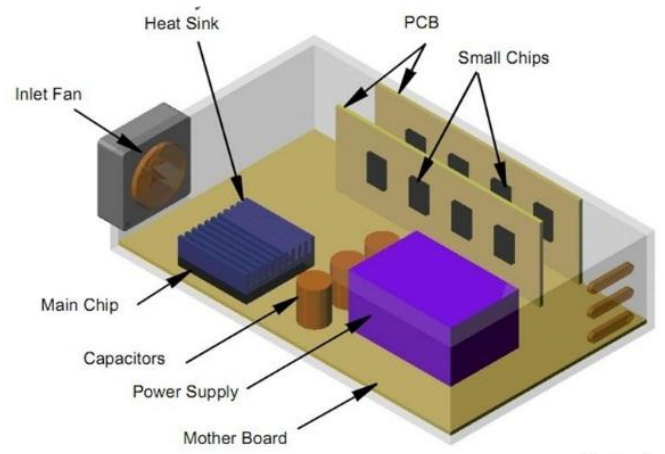

Figure 1. Simulation Method

\section{Results and Discussion}

\section{Validation}

The purpose of this validation is to ensure the results we are obtaining are correct. The results obtained will be compared with the results of previous studies by Anusaya et al (2014) [2]. This study used the temperature parameters for validation in PC motherboard.

Table 1. Comparison of temperatures on motherboard

\begin{tabular}{cccc}
\hline Results & $\begin{array}{c}\text { Anusaya, } \\
2014\end{array}$ & $\begin{array}{c}\text { Research } \\
\text { Now 2015 }\end{array}$ & $\begin{array}{c}\text { Error } \\
(\%)\end{array}$ \\
\hline $\begin{array}{c}\text { Chip } \\
\text { Temperature }\end{array}$ & 61,7 & 64,9 & $4 \%$ \\
\hline $\begin{array}{c}\text { Max Chip } \\
\text { Temperature }\end{array}$ & 91,5 & 86,9 & $5 \%$ \\
\hline
\end{tabular}

Table 1 shows that the results of this simulation show similarities compared to previous studies, the error occurring is $4 \%$ or less than $10 \%$. This indicates that this simulation is able to capture physical phenomena.

\section{Comparison contours of the refrigeration effect for different speed variations}

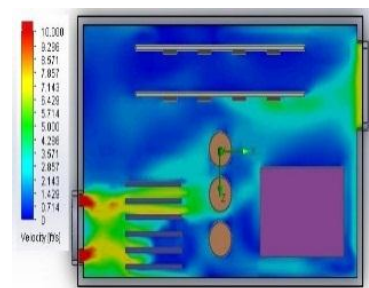

(a)



(b)



(c)

Figure 2. Contour of cooling speed (a) $V=5 \mathrm{~m} / \mathrm{s}$, (b) $\mathrm{V}=10 \mathrm{~m} / \mathrm{s}$, (c) $\mathrm{V}=15 \mathrm{~m} / \mathrm{s}$

Figure 1 was a combination of airflow velocity contours direction on the motherboard of the laptop. The image shows that the temperature at the fan inlet is lower than the temperature in the surrounding area. This is due to convection heat transfer due to greater fluid velocity at the fan inlet. While at outlet because the outlet speed is greater than speed around, there will also be heat transfer of convection, so that the temperature at the outlet is lower than the temperature around it. At the power supply temperature distribution is higher than other areas.

Comparison of temperature contours in direction of air flow on the motherboard

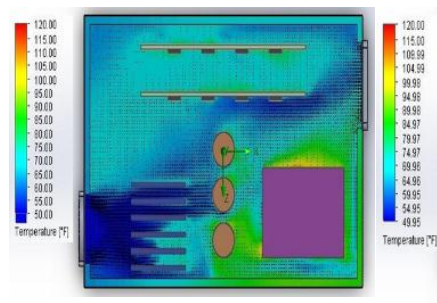

(a)

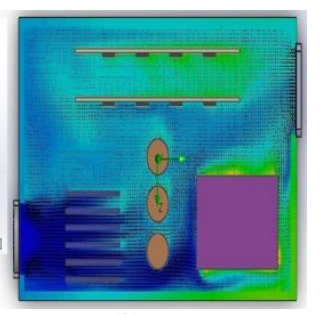

(b)

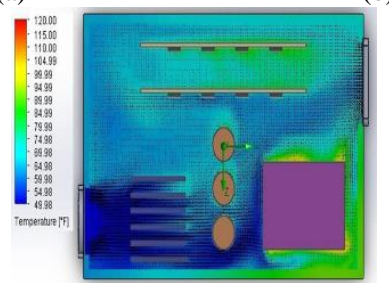

(c)

Figure 3. Temperature contours in direction of air flow on a laptop motherboard with variations in speed (a) $\mathrm{V}=5 \mathrm{~m} . \mathrm{s}$, (b) $\mathrm{V}=10 \mathrm{~m} / \mathrm{s}$, (c) $\mathrm{V}=15 \mathrm{~m} / \mathrm{s}$ 
Figure 3, shows the airflow direction contour at a speed of $15 \mathrm{~m} / \mathrm{s}$ on laptop mother board. The image shows the temperature at the fan inlet is lower than the temperature surrounding it. This is due to the heat transfer of convection due to the greater velocity of fan inlet fluid. While at the outlet because the outlet speed is greater than the velocity around it, convection heat transfer will also take place, so that the outlet temperature is lower than the temperature around it. At the distribution of the power supply temperature is higher than other areas.

\section{Comparison of speed contour is also great compared to previous researchers Zoleh Anusaya M Salwe 2014}



(a)

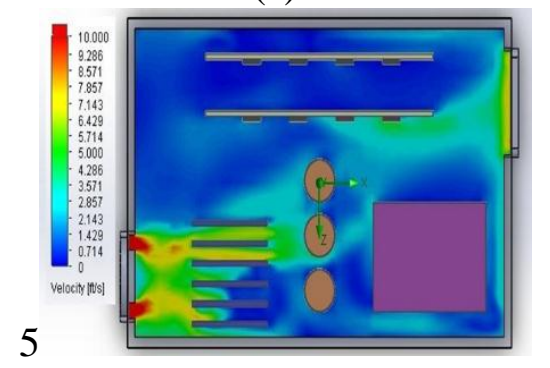

(b)

Figure 4. Comparison of speed contour between a. simulation results of Anusaya et al, 2014 with b.

Current research simulation results

Figure 4 is comparison image of the speed contour between the results of the study of Anusaya et al, 2014 and this study The picture shows that the maximum speed at the fan inlet is the speed which occurs at the motherboard inlet. After that, the fluid speed flows to other places on the mother board, including: main chip, heat sink, capacitor, PCB, power supply, and output. The figure shows that speed counters were consistent with this study among the previous research carried out by Anusaya et al, 2014.

\section{Temperature graph plot with different speed variations}

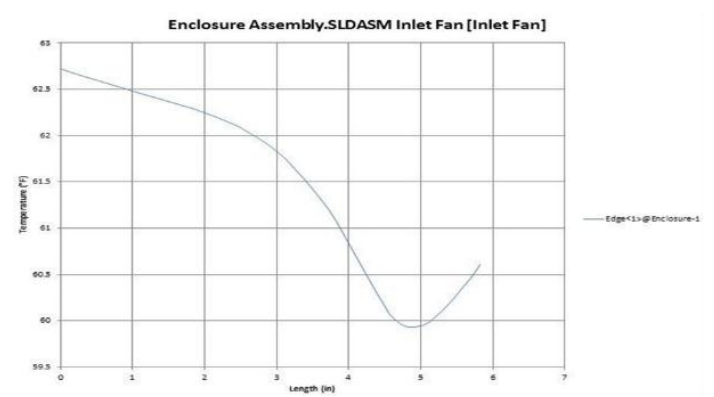

(a)

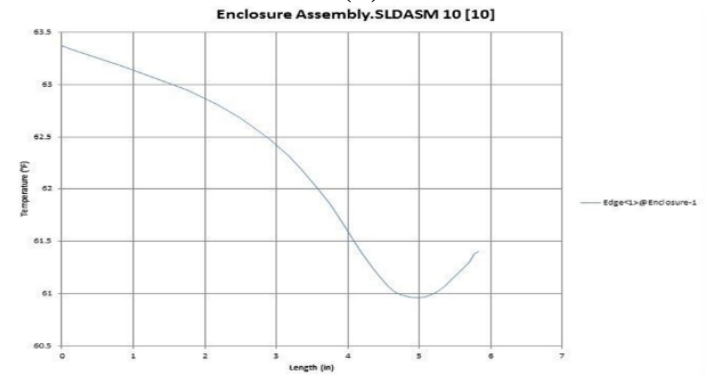

(b)

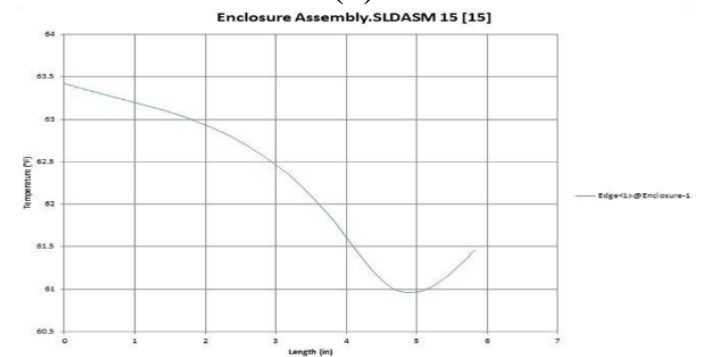

(c)

Figure 5. Temperature graph for velocity variations (a) $\mathrm{V}=5 \mathrm{~m} / \mathrm{s}$ (b) $\mathrm{V}=10 \mathrm{~m} / \mathrm{s}$ (c) $\mathrm{V}=15 \mathrm{~m} / \mathrm{s}$

Figure 5 shows the temperature distribution increases as the distance. This is cause by the convection coefficient is influenced by the velocity of the flow (Anusaya M, et al in 2014) [2] because in the initial data collection position $\mathrm{X}=0$ in that area the narrowing of the heat transfer area occurs. According to the theory of continuity with the same discharge but the area decreases the velocity will increase (Q $=\mathrm{V}$.A) with the same large velocity in the region $X=0$, the coefficient of heat transfer of the convection will shrink and cause the temperature in the $\mathrm{X}$ region is also small. As the distance increases from $X=0$ to $X=6$, the temperatures are also increases. 


\section{Conclusion}

Data analysis of simulation results in previous chapter has obtained phenomenon and characteristics of air flow velocity on laptop, so that in this study conclusions can be drawn from simulation results, the higher air flow velocity, the higher cooling that occurs.

From temperature contours can show the heat temperature collects at power supply where heating side arises due to electric current.

Simulation results with variations in air velocity were: $5,10,15 \mathrm{~m} / \mathrm{s}$ obtained with greater speed there will be large decrease in temperature, especially in power supply. This is marked by yellow area which has a higher temperature that was less than speed of other fluid flow.

\section{References}

[1] Dedy Zulhidayat Noor, Ming-Jyh Chern, Tzyy-Leng Horng. 2009. An Immersed Boundary Method to Solve fluid-Solid Interaction Problems, Comput Mech 44:447-453 DOI 10.1007/S00466-009-0384-5. 2009.

[2] Anusaya M,Salwe , Shubham, S Pande Jouned, S Khan. 2014. Effect Of Velocity And Particle Size On The Coefficient Of Heat Transfer In Fluidized Bed Heat Exchanger, International Jurnal Of Enggineering Research And General Science, Volume 2,Issue2,Feb-Maret 2014.

[3] Jin Zhao, Jianzhao Wang, Zhenhai Guo, Yanling Guo, Wantao Lin, Yihuo Lin. 2019. Multi-Step Wind Speed Forecasting Based On Numerical Simulations And An Optimized Stochastic Ensemble Method. Journal Elsevier Applied Energy.

[4] Xin Hou, Ji Chen, Huijun Jin, Pengfei Rui, Jingyi Zhao, Qihang Mei. 2019. Thermal Characteristics of Cast-InPlace Pile Foundations in Warm Permafrost at Beiluhe on Interior Qinghai-Tibet Plateau: Field Observations and Numerical
Simulations. Journal Elsevier Technical Paper.

[5] Zerui Sun, Changgen Shi, Fei Xu, Ke Feng, Chunhua Zhou, Xiaoming Wu. 2020. Detonation Process Analysis and Interface Morphology Distribution of Double Vertical Explosive Welding By SPH 2D/3D Numerical Simulation and Experiment. Journal Elsevier Material and Design.

[6] Abdulmajeed A. Ramadhan, N. Kapur, J.L. Summers, H.M. Thompson. 2018. Numerical Development of EHD Cooling System for Laptop Aplications. Journal Applied Thermal Engineering

[7] Hsio-Kang Ma, Bo-Ren Chen, JongJhih Gao, Cheng-Yao Lin. 2009. Development of an OACPmicropump Liquid Cooling System in a Laptop. Journal Elsevier International Communications in Heat and Mass Transfer.

[8] Syamsuri, Novi Indah Riani. 2017. Numerical Cooling Simulation On Laptop Heat Sinks with Variations of Different Airflow Speeds. Journal of Mechanical Engineering Education Vanos.

[9] Syamsuri, Hasan Syafik M, Yudho Putro Iswanto. 2018. Study The Effect of Angle of Attack On Flow Characteristics At Racing Bike Helmet Using CFD. Journal MATEC Web of Conferences IMIEC 2018. 